\title{
Adoption of new drugs by physicians: a survival analysis
}

Francisco Javier Garjón ${ }^{*}$, Ana Azparren ${ }^{1}$, Iván Vergara², Borja Azaola ${ }^{3}$ and Jose Ramón Loayssa ${ }^{4}$

\begin{abstract}
Background: New drugs often substitute others cheaper and with a risk-benefit balance better established. Our aim was to analyse the diffusion of new drugs during the first months of use, examining the differences between family physicians and specialists.

Methods: Prescription data were obtained of cefditoren, duloxetine, etoricoxib, ezetimibe, levocetirizine, olmesartan, pregabalin and tiotropium 36 months after their launching. We obtained the monthly number of prescriptions per doctor and the number prescribers of each drug by specialty.

After discarding those with less than 10 prescriptions during this period, physicians were defined as adopters if the number of prescriptions was over the 25th percentile for each drug and level (primary or secondary care). The diffusion of each drug was studied by determining the number of adopter family physicians throughout the study period. Among the group of adopters, we compared the month of the first prescription by family physicians to that of other specialists using the Kaplan-Meier method.
\end{abstract}

Results: The adoption of the drugs in primary care follows an exponential diffusion curve that reaches a plateau at month 6 to 23. Tiotropium was the most rapidly and widely adopted drug. Cefditoren spread at a slower rate and was the least adopted. The diffusion of etoricoxib was initially slowed down due to administrative requirements for its prescription. The median time of adoption in the case of family physicians was 4-6 months. For each of the drugs, physicians of a specialty other than family physicians adopted it first.

Conclusions: The number of adopters of a new drug increases quickly in the first months and reaches a plateau. The number of adopter family physicians varies considerably for different drugs. The adoption of new drugs is faster in specialists. The time of adoption should be considered to promote rational prescribing by providing timely information about new drugs and independent medical education.

Keywords: Diffusion of innovation, Drug prescriptions, Drug utilization, Physician's practice patterns, Survival analysis

\section{Background}

Drugs are an essential part of medical practice and represent a high economic burden. The pattern of prescription varies among physicians and many influences on the doctor's prescription other than the clinical indications have been described [1-3]. In this context, the introduction and diffusion of new drugs on the market is an issue of special transcendence. The diffusion of a

\footnotetext{
* Correspondence: jgarjonp@navarra.es

'Servicio Navarro de Salud. Servicio de Prestaciones Farmacéuticas, Plaza de la Paz s/n, E-31002 Pamplona, Spain

Full list of author information is available at the end of the article
}

new drug can be defined as its dissemination through different channels over time among physicians [4].

The substitution of established therapies for new drugs is often inappropriate because of lack of improvements in effectiveness, when unknown side effects cannot be ruled out at the time of marketing [5] and the prices are disproportionate to the alleged benefits [6,7]. However, a delayed uptake of effective innovations supported by clinical investigation has also been observed, resulting in non-optimal treatments for some patients [8].

There is a substantial difference in prescribing a new drug for the first time ever and to prescribe it routinely 
[9]. A physician is an adopter of a new drug if he incorporates it to his personal formulary and hence prescribes it regularly.

Our study aims to analyze the diffusion of eight new drugs during the first months of use and examine the differences in the adoption of these new drugs between family physicians and specialists. We focus in adopters because we are interested in doctors who have changed their prescribing behaviour. The dynamics of this process is important to design educational or administrative activities.

Even though this study cannot identify all the factors that influence the diffusion of these drugs, it may be useful for generating hypothesis about the characteristics of the drugs that influence its diffusion and the relationship with the medical specialty. All this information could be used for establishing the timing of dissemination of scientific information on new drugs and for identifying sectors of doctors where a special attention would be required.

\section{Methods}

We performed a retrospective study with the prescription database of the Navarre Health Service (Servicio Navarro de Salud - Osasunbidea, SNS-O) using data from 2003 to 2007. This database includes monthly information of all prescriptions financed by the SNSO. By Spanish law, the aggregate information resulting from processing prescriptions of the National Health System is of public domain and its evaluation is competence of health services [10]. In Navarre the task belongs to the Pharmaceutical Benefits Service (Servicio de Prestaciones Farmacéuticas), which is part of the SNS-O. The Pharmaceutical Benefits Service provides feed back information to doctors about the use of new medicines, so the name of the doctor is included in the database.

Ethics statement: The study was approved by the scientific council of the Health Department of the Government of Navarre. We used a database that did not include patient information. Therefore, no ethical approval was necessary.

The SNS-O provides tax-financed health care in Navarre (Spain) and it covers pharmaceutical benefits to approximately 600,000 persons (95\% of the population). Doctors working for the SNS-O are employees of it. All of them work in group practices or in hospitals. Specialists normally write the first prescription of the drug they indicate.

From the drugs marketed between 2003 and 2007, eight drugs with different indications were chosen (Table 1). All of them are suitable for use both at primary and at secondary care levels and were indicated in common disorders in clinical practice. During the study period those drugs were the latest licensed of their therapeutic group for their indications. The Drug Assessment Working Group of the SNS-O evaluates the degree of therapeutic innovation of the new drugs and provides drug assessment reports to the doctors belonging to the SNS-O. The degree of therapeutic innovation of each new drug is determined in accordance with criteria of level of evidence, efficiency, safety, convenience and cost, all in comparison with alternative therapies.

In the case of etoricoxib, a prior authorization was required for its prescription at the onset of marketing. This requirement was withdrawn 24 month after its launching.

For each drug, the month in which the first prescription was issued was considered month 1 and a follow up of the drug prescription was carried out for a period of up to 36 months.

Doctors who had signed some prescription in 2003 and also in 2007 were eligible.

We select those who prescribed any of the eight studied drugs. From this group we analyzed the number of prescriptions per physician at months $2,3,6,12,24$ and 36 in family physicians.

To define the group of adopters of a drug, we first excluded those physicians who prescribed it sporadically (less than 10 prescriptions during the 36 month study period). Then for each drug and level (primary care or secondary care) we selected physicians whose number of prescriptions was over the 25th percentile of prescriptions per drug and physician within each level. Using this criterion we deal with the differences in the number of patients, contacts and case-mix.

The diffusion of each drug was studied among the group of adopter physicians. The adoption time of a drug was defined as the month in which the physician makes the first prescription. We plotted the curve of cumulative number of adopter primary care physicians over time after the launching of the drug. A KaplanMeier survival analysis was performed with the adoption time. The log rank test was used to test differences between family physicians and the different specialists. Statistical analysis was performed using the program PASW Statistics ${ }^{\circledR}$ for Windows (version 17.0, SPSS Inc.).

\section{Results}

Of 1248 physicians with a prescription, 904 prescribed some of the selected drugs and 441 were considered as adopters (Figure 1).

\section{Prescribing family physicians and mean of prescriptions}

Table 2 shows the number of family physicians who have prescribed each studied drug and the mean of prescriptions per physician at different times. 
Table 1 Characteristics of the studied drugs

\begin{tabular}{|c|c|c|c|c|c|}
\hline Drug & Launching & $\begin{array}{l}\text { Degree of } \\
\text { therapeutic } \\
\text { Innovation* }\end{array}$ & Approved indications & $\begin{array}{l}\text { Cost/ } \\
\text { DDD }\end{array}$ & Alternatives (cost/DDD) \\
\hline Cefditoren & Sep-04 & $\begin{array}{l}\text { No therapeutic } \\
\text { innovation }\end{array}$ & $\begin{array}{l}\text { Pneumonia, exacerbation of chronic bronchitis, } \\
\text { pharyngitis, tonsillitis, skin infections }\end{array}$ & $\begin{array}{l}€ 4.47 \\
-6.26\end{array}$ & $\begin{array}{l}\text { Amoxicillin-clavulanate }(€ 0.68) \\
\text { Cefuroxime axetil }(€ 2.27)\end{array}$ \\
\hline Duloxetine & Dec-05 & $\begin{array}{l}\text { No therapeutic } \\
\text { innovation }\end{array}$ & $\begin{array}{l}\text { Neuropathic pain, depresión, generalised anxiety disorder } \\
\text { (from jul-08) }\end{array}$ & $€ 1.99$ & $\begin{array}{l}\text { Amitriptyline }(€ 0.11) \\
\text { Fluoxetine }(€ 0.24) \\
\text { Paroxetine }(€ 0.79)\end{array}$ \\
\hline Etoricoxib & Jul-04 & $\begin{array}{l}\text { No therapeutic } \\
\text { innovation }\end{array}$ & $\begin{array}{l}\text { Osteoarthritis, rheumatoid artritis, acute gouty artritis, } \\
\text { ankylosing spondylitis (from sep-08) }\end{array}$ & $€ 1.74$ & $\begin{array}{l}\text { Ibuprofen }(€ 0.24) \\
\text { Diclofenac }(€ 0.17) \\
\text { Naproxen }(€ 0.38)\end{array}$ \\
\hline Ezetimibe & Mar-04 & Insufficient evidence & $\begin{array}{l}\text { Primary hypercholesterolaemia, homozygous familial } \\
\text { hypercholesterolaemia, homozygous sitosterolaemia }\end{array}$ & $€ 1.91$ & \\
\hline Levocetirizine & Apr-03 & $\begin{array}{l}\text { No therapeutic } \\
\text { innovation }\end{array}$ & Allergic rhinitis, chronic idiopathic urticaria & $€ 0.56$ & Cetirizine $(€ 0.29)$ \\
\hline Olmesartan & May-04 & $\begin{array}{l}\text { No therapeutic } \\
\text { innovation }\end{array}$ & Hypertension & $€ 0.92$ & $\begin{array}{l}\text { Losartan (€0.92) Enalapril } \\
(€ 0.13)\end{array}$ \\
\hline Pregabalin & Jan-05 & $\begin{array}{l}\text { No therapeutic } \\
\text { innovation }\end{array}$ & $\begin{array}{l}\text { Neuropathic pain, epilepsy, generalised anxiety disorder } \\
\text { (from mar-06) }\end{array}$ & $€ 2.57$ & $\begin{array}{l}\text { Gabapentin (€0.19) } \\
\text { Amitriptyline }(€ 0.11)\end{array}$ \\
\hline Tiotropium & Jan-03 & $\begin{array}{l}\text { Modest therapeutic } \\
\text { innovation }\end{array}$ & Chronic obstructive pulmonary disease & $€ 1.91$ & Ipratropium (€0.28) \\
\hline
\end{tabular}

*No therapeutic innovation: The new drug has no added value over other drugs which are already available in the market for the same indication. Modest therapeutic innovation: The new drug provides more posology comfort. Insufficient evidence: Available evidence is insufficient or inconclusive, or lacks good quality clinical trials including an adequate comparative drug.

DDD defined daily dose.

Information provided in the reports of the Navarre Drug Assessment Working Group [Available in: http://www.navarra.es/home_es/Temas/Portal+de+la+Salud/ Profesionales/Documentacion+y+publicaciones/Publicaciones+tematicas/Medicamento/BIT/].

Rate of adoption of the drugs among physicians in each specialty

The diffusion of drugs among adopter family physicians is presented in Figure 2.

The adoption of the new drugs under study in primary care shows a similar pattern, represented by an exponential diffusion curve [11]. In the first months after the launching of the drug, the number of adopters increased rapidly to finally reach a plateau. Curves show different slopes (speed of adoption) and different heights (number

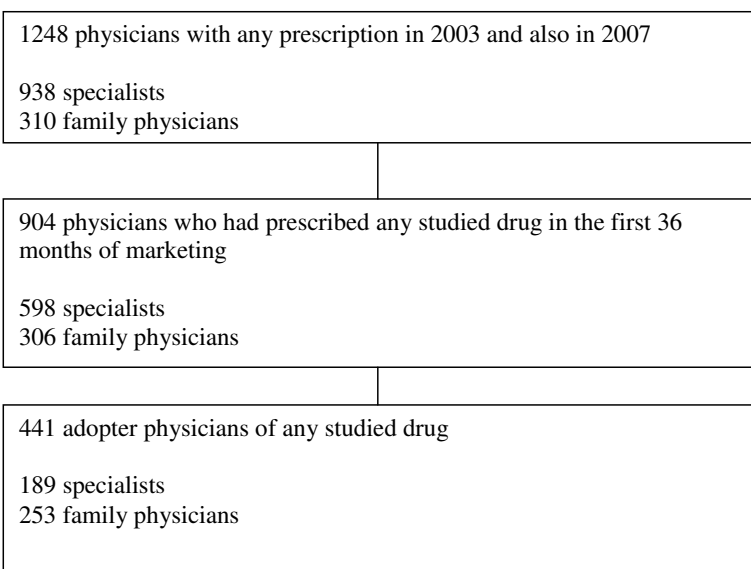

Figure 1 Flow diagram of doctors who eventually adopted the drugs). The curves reach plateaus in different months, between 6 and 23, reflecting different rates of diffusion of the drugs.

Tiotropium was the most rapidly disseminated and most widely adopted drug. Cefditoren spread at the slowest rate and was the least adopted. Etoricoxib was an exception because it did not reach a plateau during the study period.

The differences between specialties in adoption of the drugs under study are shown in Table 3. Although each drug is prescribed by several specialties, the proportion of adopters is very different. For each drug there is one specialty that adopted it before family physicians and with a percentage of adopters of at least $50 \%$ : otolaryngology for cefditoren, psychiatry for duloxetine, rheumatology for etoricoxib, endocrinology for ezetimibe, allergology for levocetirizine, rheumatology for pregabalin and pneumology for tiotropium. Olmesartan was an exception since the percentage of family physician adopters was far larger than specialists although cardiology adopted it faster.

\section{Discussion}

The adoption of new drugs in primary care follows an exponential curve. In consumer research, this shape indicates consumers perceive little risk (physical or economic) associated with the innovation [11]. We believe this perception is not desirable in the field of new drugs. 
Table 2 Family physicians who prescribe each drug at different times and mean prescriptions per physician

\begin{tabular}{|c|c|c|c|c|c|c|c|c|c|c|c|c|}
\hline & \multicolumn{12}{|c|}{ Month since launching } \\
\hline & \multicolumn{2}{|r|}{2} & \multicolumn{2}{|r|}{3} & \multicolumn{2}{|r|}{6} & \multicolumn{2}{|r|}{12} & \multicolumn{2}{|r|}{24} & \multicolumn{2}{|r|}{36} \\
\hline & $\mathrm{n}$ & Mean (SD) & $\mathrm{n}$ & Mean (SD) & $\mathrm{n}$ & Mean (SD) & $\mathrm{n}$ & Mean (SD) & $\mathrm{n}$ & Mean (SD) & $\mathrm{n}$ & Mean (SD) \\
\hline Cefditoren & 7 & $3.6(4.2)$ & 26 & $2.3(1.9)$ & 30 & $3.4(2.8)$ & 32 & $3.3(5.7)$ & 44 & $2.0(2.2)$ & 51 & $2.6(2.8)$ \\
\hline Duloxetine & 38 & $1.5(0.9)$ & 67 & $2.0(1.5)$ & 125 & $2.4(2.0)$ & 172 & $3.5(2.7)$ & 176 & $5.1(3.8)$ & * & * \\
\hline Etoricoxib & 14 & $1.1(0.4)$ & 32 & $1.6(0.9)$ & 41 & $1.4(0.6)$ & 44 & $1.5(0.8)$ & 48 & $1.9(1.3)$ & 124 & $3.1(4.0)$ \\
\hline Ezetimibe & 31 & $2.0(1.4)$ & 59 & $2.0(1.5)$ & 94 & $2.3(1.9)$ & 148 & $2.7(2.5)$ & 200 & $4.0(3.6)$ & 191 & $4.6(3.8)$ \\
\hline Levocetirizine & 8 & $1.6(0.9)$ & 9 & $1.6(0.7)$ & 21 & $1.2(0.4)$ & 75 & $2.2(1.6)$ & 132 & $2.4(1.7)$ & 158 & $3.0(2.8)$ \\
\hline Olmesartan & 36 & $1.8(1.0)$ & 49 & $2.2(1.3)$ & 89 & $2.3(1.7)$ & 131 & $3.4(3.7)$ & 165 & 4.1 (4.8) & 182 & $4.7(5.5)$ \\
\hline Pregabalin & 14 & $1.3(0.5)$ & 31 & $1.7(1.4)$ & 80 & $1.8(1.0)$ & 137 & $2.3(1.8)$ & 181 & $3.7(2.7)$ & 198 & $5.1(3.6)$ \\
\hline Tiotropium & 80 & $2.3(1.6)$ & 127 & $2.9(2.4)$ & 215 & $3.5(2.6)$ & 244 & $5.9(4.0)$ & 264 & $7.4(4.9)$ & 264 & $8.5(5.4)$ \\
\hline
\end{tabular}

$n$ number of physicians. $S D$ standard deviation.

*Data of $36^{\text {th }}$ month of duloxetine are no comparable due to changes in medical staff.

The adoption rate of a drug can have been influenced by several factors apart from how effectively it is marketed.

\section{Degree of therapeutic innovation}

It is determined in accordance with criteria of evidence, efficiency, safety, convenience and cost, all in comparison with alternative therapies. Tiotropium was the most widely and quickest adopted drug by family physicians. It was the only studied drug that was rated as a therapeutic innovation but we cannot affirm that it is the main reason for its rapid diffusion. In the literature, however, this quality is not related consistently with adoption $[12,13]$. Personal perceptions about

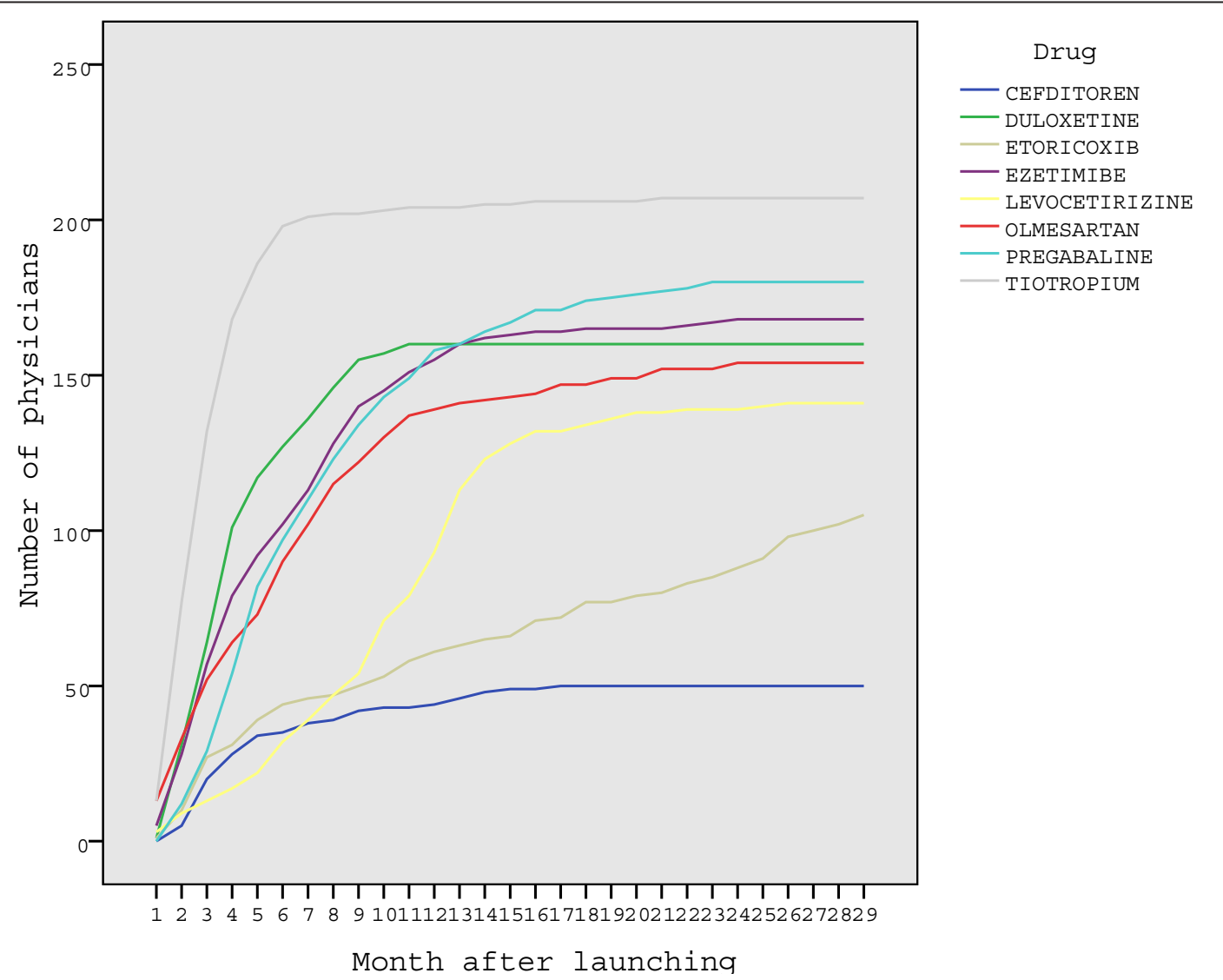

Figure 2 Cumulative number of adopter family physicians who prescribe each drug over time. 
Table 3 Adopters per drug and specialty and time of adoption

\begin{tabular}{|c|c|c|c|c|c|c|}
\hline \multirow{3}{*}{ Drug } & \multirow{3}{*}{ Specialty } & \multirow{3}{*}{ Number of prescribers } & \multirow{3}{*}{ Number of adopters (\%) } & \multicolumn{3}{|l|}{ Time of adoption } \\
\hline & & & & \multirow[t]{2}{*}{ Median in months (intercuartile range) } & \multicolumn{2}{|c|}{$\begin{array}{l}\text { Comparison } \\
\text { with Family } \\
\text { Physicians. } \\
\text { Log-rank test }\end{array}$} \\
\hline & & & & & $\chi^{2}$ & p-value \\
\hline \multirow[t]{5}{*}{ Cefditoren } & Otolaryngology & 19 & $11(58 \%)$ & $2(2-5)$ & 6.76 & 0.01 \\
\hline & Family physicians & 232 & $50(22 \%)$ & $4(3-7)$ & & \\
\hline & Internal medicine & 22 & $4(18 \%)$ & $5(3-10)$ & 0.44 & NS \\
\hline & Emergencies & 65 & $7(11 \%)$ & $9(5-21)$ & 6.39 & 0.01 \\
\hline & Pneumology & 15 & $7(47 \%)$ & $9(8-12)$ & 1.14 & NS \\
\hline \multirow[t]{2}{*}{ Duloxetine } & Psychiatry & 36 & $22(61 \%)$ & $2(2-3)$ & 29.55 & $<0.01$ \\
\hline & Family physicians & 252 & $160(63 \%)$ & $4(3-6)$ & & \\
\hline \multirow[t]{4}{*}{ Etoricoxib } & Rheumatology & 6 & $3(50 \%)$ & $2(1-8)$ & 8.08 & $<0.01$ \\
\hline & Traumatology & 55 & $21(38 \%)$ & $3(2-15)$ & 1.97 & NS \\
\hline & Family physicians & 230 & $105(46 \%)$ & $10(3-20)$ & & \\
\hline & Rehabilitation & 14 & $2(14 \%)$ & $11(11-26)$ & 0.51 & NS \\
\hline \multirow[t]{3}{*}{ Ezetimibe } & Cardiology & 16 & $6(38 \%)$ & $2(1-3)$ & 8.13 & $<0.01$ \\
\hline & Endocrinology & 11 & $8(73 \%)$ & $3(2-3)$ & 10.95 & $<0.01$ \\
\hline & Family physicians & 258 & $168(65 \%)$ & $5(3-8)$ & & \\
\hline \multirow[t]{5}{*}{ Levocetirizine } & Otolaryngology & 19 & $8(42 \%)$ & $1(1-4)$ & 24.14 & $<0.01$ \\
\hline & Allergology & 10 & 10 (100\%) & $4(2-7)$ & 4.96 & 0.03 \\
\hline & Emergencies & 44 & $4(9 \%)$ & $4(4-12)$ & 0.73 & NS \\
\hline & Dermatology & 15 & $12(80 \%)$ & $9(2-12)$ & 1.54 & NS \\
\hline & Family physicians & 264 & $141(53 \%)$ & $10(7-13)$ & & \\
\hline \multirow[t]{3}{*}{ Olmesartan } & Cardiology & 15 & $3(20 \%)$ & $1(1-2)$ & 17.23 & $<0.01$ \\
\hline & Internal medicine & 21 & $3(14 \%)$ & $2(2-13)$ & 0.04 & NS \\
\hline & Family physicians & 256 & $154(60 \%)$ & $6(3-9)$ & & \\
\hline \multirow[t]{6}{*}{ Pregabalin } & Anesthesiology & 8 & $3(38 \%)$ & $2(2-5)$ & 8.45 & $<0.01$ \\
\hline & Neurology & 17 & $8(47 \%)$ & $3(2-4)$ & 12.1 & $<0.01$ \\
\hline & Rheumatology & 6 & $6(100 \%)$ & $3(2-4)$ & 9.83 & $<0.01$ \\
\hline & Rehabilitation & 23 & 17 (74\%) & $5(2-7)$ & 2.94 & NS \\
\hline & Family physicians & 275 & $180(65 \%)$ & $6(4-10)$ & & \\
\hline & Traumatology & 56 & $17(30 \%)$ & $6(4-9)$ & 0.87 & NS \\
\hline \multirow[t]{3}{*}{ Tiotropium } & Pneumology & 15 & 14 (93\%) & $1(1-2)$ & 49.18 & $<0.01$ \\
\hline & Internal medicine & 30 & $14(47 \%)$ & $2(2-5)$ & 0.13 & NS \\
\hline & Family physicians & 297 & 207 (70\%) & $3(2-4)$ & & \\
\hline
\end{tabular}

NS: $p>0.05$

effectiveness, safety profile and advantages over alternatives are consistent factors that influence the decision to adopt a drug $[14,15]$. Cost does not seem to be a determining factor $[3,16]$.

\section{Me-too drugs}

They are drugs chemically related with a previous approved drug, with the same mechanism of action and indications. Since there is a perception of well known drugs, its adoption can be facilitated. On the other hand, there are few reasons for adopting them due to their scarce therapeutic advantages. Olmesartan belongs to a commonly used class of drugs, angiotensin II receptor blockers, employed in the management of hypertension. Although it was not massively adopted, the percentage of adopters was greater for family physicians than for specialists. It can be explained by their indication which is managed almost entirely in primary care.

Levocetirizine, a isomer of cetirizine, is an example of strategy to prolong the life of drug when the patent expires in the face of competition from generic drugs [17]. 


\section{New mechanism of action}

Doctors are likely to prescribe drugs with a new mechanism of action [3]. Ezetimibe has the same indications than effective therapies like statins; but its mechanism of action is different. The decreasing lipid targets in guidelines may have promoted its adoption as add-on therapy.

\section{Range of indications}

Pregabalin was adopted initially at a not very fast rate, but at the end of the study period was adopted by a large number of physicians. This may be because the range of its indications was increased. Besides, pregabalin is indicated for diseases with a poor response to therapies like neuropathic pain or generalised anxiety disorder.

Duloxetine has the indication of depression, a very common condition that explains the wide adoption for psychiatrists and for family physicians. Surprisingly, although it is also indicated in neuropathic pain, in contrast with pregabalin, it was not adopted by the specialties that deal with this disease (anaesthesiology, neurology and rheumatology).

\section{Policies}

Cefditoren had the lower number of adopters in primary care. The policy of rational use of antibiotics may have limited its utilization.

Etoricoxib initially required an endorsement before dispensation, which was subsequently withdrawn allowing for wider prescription henceforth. The effect of an authorization requirement for COX-2 inhibitor drugs has been determined in the U.S.A [18].

\section{Chronic versus acute use}

Due to the use of ceftditoren in acute diseases, there is not induced prescription (treatment initiated in secondary care and followed in primary care). This can have contributed to its low adoption.

The seasonal use of levocetirizine can be responsible for its long adoption time.

The results from this study suggest that secondary care plays a key role in the adoption of new drugs by family physicians. Drugs are adopted earlier by specialists. This fact could be justified when the drugs are indicated in a disease managed mainly by specialists. The early adopter role of the specialists may be due to various factors: differences in sources of information $[3,16]$, differences in the attitude towards evidencebased medicine [19] and differences in the tolerance to uncertainty [20].

Specialists' prescription influence family physicians by induced or imitated prescriptions $[3,21]$. Our study can not differentiate between prescriptions originating from primary care and induced.

Why some specialties have a low percentage of adopters, even lower than family physicians? Specialists always choose the drugs they use. However, the family physician often follows the prescriptions of the specialists. Another reason can be the existence of sub-specialties (e.g. a neurologist who treats mainly Parkinson disease can use few antiepileptic drugs).

This study focuses on adopters because our interest is the process of inclusion of a drug in the therapeutic arsenal of physicians and not the occasional prescription. The definition of an adopter of a new drug was ad hoc. We do not categorise physicians as early or late adopters, as is common in the literature about diffusion of new drugs $[4,12,22]$. The notion that early adoption is a personal characteristic has been challenged [9].

We use time-to-event analysis to compare adoption times between primary and secondary care. We find this model useful to describe the process of adoption because time is a key variable for designing intervention strategies. Another study used a Cox model to compare single-handed to partnership practices [9].

This study has several limitations. The analysis is limited to eight drugs and the results may not be generalized. We could not differentiate between prescriptions originating from primary care and those induced.

The median time of adoption for family physicians is between 4 and 6 months for the majority of the drugs. This period is shorter for specialists. New drugs are adopted before safety and cost-effectiveness are well established. At the time a new drug reaches the market, information about its efficacy and safety came only from clinical trials. Generally, they are too short, with too few patients and too narrow. Only selected patients are included. Those older, non compliant, with polypharmacy or with multiple pathologies are often excluded. This makes impossible the accurate identification of adverse effects. The selection of patients in clinical trials and the reliance in subrogate end points prevent from establishing the effectiveness in real life situations and hence the cost- effectiveness.

"Do Not Rush to Use Newly Marketed Drugs" has been proposed as a principle of judicious prescribing. Older drugs are generally safer owing to their longer track record. Even, to wait 7 years before using a new drug has been advocated, based on data showing that it often takes 5 to 10 years to identify significant adverse effects [23]. This is in great contrast with the adoption rate in our study.

New drugs often replace others better known and cheaper. The short period of adoption should be taken into account if we consider the implementation of 
measures aimed at controlling the diffusion of a new drug (e.g. independent drug information or medical education activities). Albeit there is a large room for improvement in drug regulatory agencies [23], health systems have the responsibility to design strategies to promote the cautious adoption of innovative drugs; inhibit the adoption of the non-innovative ones; and avoid the premature abandonment of established therapies. If there is a risk of a delayed introduction of truly innovative products has to be balanced against the risk of treating patients with a drug before its safety was well established.

Ideally, information about the relative efficacy and safety of a new drug should be known before launching or at least before being adopted. This information has to be evidence-based and independent of the pharmaceutical industry. Drug bulletins publish reviews of new drugs trying to help their readers recognise the products that really are an advance and which deserve to be included in the list of drugs they use. Outreach visits, continuing education meetings and workshops are also used. All those instruments show limited effectiveness. Multifaceted interventions are more effective than simply delivering information [24].. It is necessary to consider that interventions are often carried out against aggressive marketing campaigns of the pharmaceutical industry that can promote inappropriate prescription [25]. Therefore, it should be recognised that modifying prescribing behaviour is difficult. The design of interventions should have a wider scope taking into account the attitudes and beliefs of doctors, and the existence of professional networks both formal and informal $[3,16,19]$. The imposition of administrative requirements could be effective.

It is necessary to explore the influence of factors such as the relationship with the pharmaceutical industry, continuing education and independent drug information. Moreover, the identification of other factors could help explain the dynamics of new drugs adoption in order to design better strategies for promoting the selection of cost-effective therapies.

\section{Conclusions}

The number of adopters of a new drug increases quickly in the first months and reaches a plateau. The number of adopter family physicians varies considerably for different drugs. The adoption of new drugs is faster in specialists. The time of adoption should be considered to promote rational prescribing by providing timely information about new drugs and independent medical education.

\section{Acknowledgements}

This study was funded by a grant from the Health Department of the Government of Navarre (Resolución 2538/2008, 28 nov, n. 64).

\section{Author details}

${ }^{1}$ Servicio Navarro de Salud. Servicio de Prestaciones Farmacéuticas, Plaza de la Paz s/n, E-31002 Pamplona, Spain. ${ }^{2}$ Servicio Navarro de Salud. Centro de Salud de Lodosa, Lodosa, Spain. ${ }^{3}$ Servicio Navarro de Salud. Sección de Evaluación y Calidad en Atención Primaria, Pamplona, Spain. ${ }^{4}$ Servicio Navarro de Salud. Centro de Salud de Huarte, Huarte, Spain.

\section{Authors' contributions}

All authors participated in the design of the study and the discussion of findings. FJG and AA executed the data management. JRL drafted the manuscript. FJG, AA, IV and BA revised the manuscript. All authors read and approved the final manuscript.

\section{Competing interests}

IV has received payment for educational presentations from Novartis and Esteve. BA has received payment for educational presentations from GSK and reimbursement of travel expenses from MSD and Pfizer. JRL has received payment for educational presentations from Novartis and reimbursement of travel expenses from Esteve, Novartis and Pfizer. Both FJG and AA declare that they have no conflict of interest.

Received: 12 April 2011 Accepted: 8 March 2012

Published: 8 March 2012

\section{References}

1. Wun YT, Chan CS, Dickinson JA: Determinants of physicians' attitude towards prescribing. J Clin Pharm Ther 2002, 27:57-65.

2. Buusman A, Andersen M, Merrild C, Elverdam B: Factors influencing GPs' choice between drugs in a therapeutic drug group. A qualitative study. Scand J Prim Health Care 2007, 25:208-213.

3. Mason A: New medicines in primary care: a review of influences on general practitioner prescribing. J Clin Pharm Ther 2008, 33:1-10.

4. Steffensen FH, Sorensen HT, Olesen F: Diffusion of new drugs in Danish general practice. Fam Pract 1999, 16:407-413.

5. Lasser KE, Allen PD, Woolhandler SJ, Himmelstein DU, Wolfe SM, Bor DH: Timing of new black box warnings and withdrawals for prescription medications. JAMA 2002, 287:2215-2220.

6. Morgan SG, Bassett KL, Wright JM, Evans RG, Barer ML, Caetano PA, Black CD: "Breakthrough" drugs and growth in expenditure on prescription drugs in Canada. BMJ 2005, 331:815-816.

7. Zara C, Torralba M, Sotoca JM, Prat A, Faixedas MT, Gilabert A: The impact of new drug introduction on drug expenditure in primary health care in Catalunya, Spain. Ann Pharmacother 2005, 39:177-182.

8. Haines A, Jones R: Implementing findings of research. BMJ 1994, 308:1488-1492.

9. Dybdahl T, Andersen M, Sondergaard J, Kragstrup J, Kristiansen IS: Does the early adopter of drugs exist? A population-based study of general practitioners' prescribing of new drugs. Eur J Clin Pharmacol 2004, 60:667-672.

10. Ley $29 / 2006$, de 26 de julio, de garantías y uso racional de los medicamentos y productos sanitarios. , Ref. BOE-A-2006-13554.(Jul 26, 2006).

11. Adoption of, Resistance to, and Diffusion of Innovations. In Consumer Behaviour.. 5 edition. Edited by: Hoyer WD, Macinnis DJ. Mason: Cengage Learning; 2008:

12. Garcia Lirola MA, Cabeza Barrera J, Rodriguez Espejo M, Alegredel Rey E, Rabadan Asensio A: Adoption of new medications by prescribing physicians. The innovator physician. Aten Primaria 2000, 25:22.

13. Tamblyn R, McLeod P, Hanley JA, Girard N, Hurley J: Physician and practice characteristics associated with the early utilization of new prescription drugs. Med Care 2003, 41:895-908.

14. Jones MI, Greenfield SM, Bradley CP: Prescribing new drugs: qualitative study of influences on consultants and general practitioners. BMJ 2001, 323:378-381.

15. Prosser $\mathrm{H}$, Walley $\mathrm{T}$ : New drug uptake: qualitative comparison of high and low prescribing GPs' attitudes and approach. Fam Pract 2003, 20:583-591.

16. Chauhan $D$, Mason A: Factors affecting the uptake of new medicines in secondary care - a literature review. J Clin Pharm Ther 2008, 33:339-348.

17. Pegler $S$, Underhill J: Evaluating the safety and effectiveness of new drugs. Am Fam Physician 2010, 82:53-57. 
18. Siracuse MV, Vuchetich PJ: Impact of Medicaid prior authorization requirement for COX-2 inhibitor drugs in Nebraska. Health Serv Res 2008, 43:435-450.

19. Skoglund I, Segesten K, Bjorkelund C: GPs' thoughts on prescribing medication and evidence-based knowledge: the benefit aspect is a strong motivator. A descriptive focus group study. Scand J Prim Health Care 2007, 25:98-104.

20. Hamann J, Adjan S, Leucht S, Kissling W: Psychiatric decision making in the adoption of a new antipsychotic in Germany. Psychiatr Serv 2006, 57:700-703.

21. Prosser H, Almond S, Walley T: Influences on GPs' decision to prescribe new drugs-the importance of who says what. Fam Pract 2003, 20:61-68.

22. Kozyrskyj A, Raymond C, Racher A: Characterizing early prescribers of newly marketed drugs in Canada: a population-based study. Eur $J$ Clin Pharmacol 2007, 63:597-604.

23. Alexander GC, O'Connor AB, Stafford RS: Enhancing prescription drug innovation and adoption. Ann Intern Med 2011, 154:833-837.

24. Gill PS, Makela M, Vermeulen KM, Freemantle N, Ryan G, Bond C, Thorsen T, Haaijer-Ruskamp FM: Changing doctor prescribing behaviour. Pharm World Sci 1999, 21:158-167.

25. Anderson GM, Juurlink D, Detsky AS: Newly approved does not always mean new and improved. JAMA 2008, 299:1598-1600.

\section{Pre-publication history}

The pre-publication history for this paper can be accessed here: http://www.biomedcentral.com/1472-6963/12/56/prepub

doi:10.1186/1472-6963-12-56

Cite this article as: Garjón et al: Adoption of new drugs by physicians: a survival analysis. BMC Health Services Research 2012 12:56.

\section{Submit your next manuscript to BioMed Central} and take full advantage of:

- Convenient online submission

- Thorough peer review

- No space constraints or color figure charges

- Immediate publication on acceptance

- Inclusion in PubMed, CAS, Scopus and Google Scholar

- Research which is freely available for redistribution

Submit your manuscript at www.biomedcentral.com/submit 